Book Review

\title{
Earth, Inc: Using Nature's Rules to Build Sustainable Profits
}

\author{
Author: Gregory Unruh \\ Reviewed by: *Shiva Kumar Srinivasan \\ Visiting Assistant Professor, Managerial Communications, IIM Kozhikode \\ *shiva@iimk.ac.in
}

This books works on a simple assumption: sustainability is not a 'journey', but a 'destination'. What this means is that the notion of sustainability is moving from being a theoretical construct to a viable set of business practices. CEOs who keep wondering whether they can afford to strike out on the path of sustainability are wasting their time; they will probably lose out on the competitive advantages that stem from not only practicing sustainability, but by developing a corporate reputation for doing so at the earliest. Pursuing the best practices that constitute sustainability is not only good for business, argues this book, it is, in fact, good business. Gregory Unruh, the author, is a business ethicist, an environmental consultant, and an expert on corporate governance at the Thunderbird School of Global Management in the United States. This book is an attempt to demonstrate that sustainability is an idea that can be visualized effectively if we invoke the 'Earth's biosphere' as an analogue of a sustainable system. Learning from the five biosphere rules that he enumerates and discusses at length will help us to not only reinvent industrial ecology as a discipline, but make it possible to incorporate techniques of 'bio-mimicry' (learning from nature and organic life forms) into both corporate strategy and business practices.

But, in order to do so, we must start with a key term in competitive strategy: 'the value chain', and the environmental impact of each of the steps in the chain which is required to convert raw material into a manufactured product. The idea here is not to situate the value chain merely in terms of the firm, but in terms of the 'biospheric context'. The environmental impact of any value chain can then be calculated. Unruh provides a few examples with numbers so that a firm has a good idea of the environmental cost in the manufacturing process, and can decide what it must do to minimize the cost for any given product or a range of products. The process of cleaning up an environmental mess, for instance, that is created through the process of production is known as 'remediation'; working out the process involved in doing so is what keeps environmental consultants busy. Unruh argues that it is much more economical to function on the plane of 'premediation', i.e. prevent environmental spills rather than correct the problem since that is as difficult as 'pushing the toothpaste back into the tube'. A sustainable model of industrial production however is possible if the ethic of premediation is practiced by following the five biospheric rules, which involve the minimization of the materials involved, the energy required, and the waste products generated in manufacturing by invoking a comprehensive notion of 'recycling' and 'remanufacturing'. The benefits that accrue from following each of these rules are set out systematically along with case-based illustrations. The five biospheric rules are the following: 'materials parsimony', 'power autonomy', 'value cycles', 'sustainable product platforms', and 'function over form'. The five chapters in the book correspond to a detailed discussion of the five rules. The conclusion sets out the evolutionary analogues from nature like the notion of the 'niche' that is relevant in terms of strategic approaches to competitive strategy, and the development of sustainable ecosystems for industry.

The first biospheric rule is 'materials parsimony'. It is based on the idea that while there may be a wide range of materials available in nature, not all the materials can be used to manufacture products since the toxic effects of all the new and even previously existing materials has not been precisely calculated. Besides, a given combination of materials may have toxic implications that may not have been anticipated before the production of a particular product. It is therefore a good idea to work only or mainly with 
materials that have been well-tested and which will not have any toxic effects. The analogue to nature here pertains to the fact that it takes only four of the existing natural elements ('carbon, hydrogen, oxygen, and nitrogen') to build living organisms; this is a simple instance of materials parsimony in the construction of organic substances. What would the implications of replicating such a system be for an industrial system of production? What if it turns out that we don't need as many different types of materials as are presently available within the repertoire of materials science? Materials parsimony is a rule in the organic world, but it is also analogous to Occam's razor in ontology and the Pareto principle in sociology. So it might be a good idea to think through the implications of this rule in the context of manufacturing as well. The benefits of doing so include reducing complexity at several levels of the value chain comprising a firm's relations with suppliers, the production process, compliance costs, toxicity, productivity, etc.

The second biospheric rule is known as 'power autonomy'. This is based on the attempt to calculate and minimize energy consumption along every step of the value chain given the environmental risks involved in being over-dependent on fossil fuels. While it is not possible to avoid fossil fuels in their entirety at this point in time, the metric that is making the rounds in environmental circles is percent of power autonomy', which is derived from non-fossil fuels in terms of total fuel consumption, and the attempts by firms to develop alternate 'energy technologies like solar, cogeneration, wind, microturbines, fuel cell and others'. The benefits of doing so include not only a reduction in energy costs, compliance costs, and processing costs, but also better customer service and environmental performance. The third biospheric rule is 'value cycles'. It means that firms must try to re-use materials in as cost effective a way as possible. This is easier said than done since even when firms can identify and estimate accurately the value of the materials that they are attempting to recycle, it may not have a cost-effective and safe way of doing so. Recycling can happen at the level of either the physical materials involved in manufacturing or at the level of components (which is higher in the 'product manufacture hierarchy'); the former is known as 'deeploop' recycling and the latter is known as 'shallow-loop' recycling. The differences between these forms of recycling, and knowing when to invoke which, and the relationship between these forms in the context of a given product line, is discussed in some detail along with case-based illustrations to help readers differentiate between these forms. The notion of recycling is analogous to the idea that nothing is wasted in the natural world given the structure of the food chain, and the role that different animals and life forms play across different niches in regulating a natural ecosystem.

The fourth biospheric rule is 'sustainable product platforms'. This is an attempt by firms to leverage 'for scale, scope, and knowledge economies' through the deployment of value cycle platforms. While economies of scale are well-known (such as the assembly line), economies of scope and economies of knowledge are often overlooked. So, for instance, Ford's Model T focused on economies of scale, but GM which had a range of automobile brands that would use common components across models attempted to compete, and did so successfully, in the 1920s, on economies of scope. It is also possible to design a system that can simultaneously leverage on economies of 'scale and scope'. The analogue from nature in terms of scale is 'population growth' while in terms of scope it is 'speciation' in evolution. Economies of knowledge attempt to take forward the learnings from the different steps of the production process and platform choices to improve the over-all process in the generation of a value chain. The analogue here is the encoding of knowledge in the DNA. And, finally, the fifth biospheric rule is the importance of 'function over form'. In nature, the maintenance of the ecosystem involves a number of 'ecological functions' that can be performed by different species in different continents.

What matters is the function that is performed rather than the actual species to which the task is delegated. If we substitute the term 'product' for 'species', it will help us to redefine the strategic approach in a business model. A well-known example of this is Xerox which began to 'lease' rather than attempt to sell its technology when it understood that what customers want is not the product (a photocopying machine), but the document that is being copied. The shift from the product orientation to 
the functional orientation has changed the fortunes of many a company, and made many functions affordable even while the products themselves may be unaffordable for individual customers or even for firms. The focus on function as opposed to a product also changes what we mean by competition in any given sector because a product orientation sets up "barriers between industries that function over form will tear down'. The development of a new ecosystem then depends on being willing to learn through the invocation of analogies from evolution, bio-mimicry, and hitherto unexplored natural phenomena. The conclusions that Unruh draws are not meant to be definitive; they are tentative forays and function more as suggestions for further research. So the reader who disagrees with any particular analogy, or who feels that the parallels could have been drawn out more extensively, should not incorrectly infer that it is not worth the while to learn from the natural sources invoked in this book. The reader should instead see this book as an invitation to explore these analogues in his own turn, or learn to situate his or her own thought patterns when they work on naturalistic assumptions, as they often do in forms of strategic thinking, that remain unconscious. The significance of this book for academics, students, and practitioners is that it ushers in a new framework for thinking about sustainability by arguing that prevention (premediation) is better than a cure (remediation). It is therefore important to set up an ethos of industrial design that is linked to the challenges of industrial ecology as a discipline and sustainability as a form of practical intervention while setting up industrial communities and townships in the years to come. 